\title{
EL REY DE TENERIFE QUE VIAJÓ A VENECIA EN 1497: NUEVOS DOCUMENTOS
}

\author{
Alberto Quartapelle*
}

\section{RESUMEN}

En los primeros meses de 1496, Alonso de Lugo finalizó la conquista de la isla de Tenerife y, en señal de triunfo, llevó a los nueve jefes aborígenes vencidos ante los Reyes Católicos. Desde el momento en que los menceyes guanches fueron acogidos en la Corte no se tuvo más noticias de la mayoría de ellos. En este artículo se analizará la suerte del mencey más famoso y más bello, que, supuestamente, fue donado por los Reyes Católicos al embajador de Venecia, Francesco Capello, y que, meses después, viajó a la ciudad del Adriático. Nuevos documentos encontrados en Venecia ponen en tela de juicio esta reconstrucción de los hechos y abren la posibilidad de que el «rey de Tenerife» llegado a Venecia fuera uno de los caciques caníbales de las islas del Caribe traídos por Colón de regreso de su segundo viaje en 1496. Palabras Clave: Sanudo, mencey, Tenerife, Venecia, 1496.

\section{THE KING OF TENERIFE WHO TRAVELED TO VENICE IN 1497: NEW DOCUMENTS}

\section{Abstract}

During the first months of 1496, Alonso de Lugo ended the conquest of the island of Tenerife and, as a sign of triumph, led the nine aboriginal chiefs defeated to the presence of the Catholic Monarchs. From the moment the Guanche menceyes were received in the Court, there was no more news about most of them. This article will analyse the fate of the most famous and most beautiful mencey, who, supposedly, was donated by the Catholic Monarchs to the ambassador of Venice, Francesco Capello, and who, months later, travelled to the city of the Adriatic. New documents found in Venice call into question this reconstruction of the facts and open the possibility that the «king of Tenerife» arrived in Venice was just one of the cannibal caciques of the Caribbean islands brought by Columbus back from his second trip in 1496.

Keywords: Sanudo, Mencey, Tenerife, Venice, 1496. 


\section{INTRODUCCIÓN}

Uno de los acontecimientos más interesantes de la historia de las Islas Canarias es la suerte de los últimos menceyes de Tenerife tras su viaje a la Corte de los Reyes Católicos en 1496. Como es sabido, una vez finalizada la conquista de la isla, el capitán Alonso de Lugo llevó ante los monarcas castellanos ${ }^{1}$ a los nueve reyes guanches en señal de triunfo y como muestra de sumisión de los aborígenes. Hasta ahora solo se ha tenido noticia de la suerte de cinco de aquellos.

Al menos uno, don Diego de Adeje, logró regresar a Tenerife y su fidelidad a Lugo le valió el reparto de tierras en el fértil valle de Masca para vuestros ganados e para que fagáis vuestras heredades. Sabemos que residió ininterrumpidamente en la isla, datándose su muerte entre el 11 de julio de 1504, última fecha en la que se le entregaron tierras, y el 17 de noviembre de $1505^{2}$.

De un segundo, don Fernando de Anaga, hay noticias que atestiguan su presencia en Gran Canaria, de donde, en 1502, hizo llegar una queja a la Corona por la conducta de Alonso de Lugo: «Que al tiempo que por nuestro mandado se pasó de la dicha ysla de Thenerife a esa dicha ysla de la Gran Canaria, dis que Alonso de Lugo, nuestro governador de la dicha ysla de Tenerife, no le dexo pasar su hazienda, segund que por nos le avia sido mandado" ${ }^{3}$. Los motivos de ese exilio podrían fundarse en la comprensible política regia de evitar que algunos de los antiguos líderes aborígenes residieran en Tenerife y pudieran fomentar una rebelión ${ }^{4}$.

Del mencey de Abona solo sabemos que probablemente fuera joven al momento de la conquista, que una hermana y los cuatro hijos vivieron en Tenerife, y que murió antes de 1510, cuando su nombre aparece en un documento en el que se nombra a un don Pedro, guanche, hijo del rey de Abona, ya difunto...5.

De un cuarto, el mencey Belicar de Icod, bautizado con el nombre de don Enrique Canario, nos han llegado unas pocas informaciones que lo ubican en la Corte del príncipe don Juan. Después de la muerte del príncipe, fue vendido como esclavo por el cortesano Pedro Patińo hasta que, en 1500, los reyes le reconocieron

* Alberto Quartapelle. https://independent.academia.edu/AQuartapelle. E-mail: cronicascanarias@gmail.com.

${ }^{1}$ Acerca de la división de la isla en nueve menceyatos ver Bonnet, B.: «El mito de los nueve menceyes", Revista de Historia Canaria, n. ${ }^{\circ} 2$ (1956). pp. 1-17 y Serra Ràfols, E. y De la Rosa Olivera, L.: «Los reinos de Tenerife», Tagoro, Instituto de Estudios Canarios (1944).

2 De la Rosa Olivera, L. (1956): «Notas sobre los reyes de Tenerife y sus familias», Revista de Historia, n. ${ }^{\circ} 115-116$, p. 6.

3 AGS, RGS, 22 de febrero de 1502. En Gambín García, M.: «Un rey guanche en la corte de los Reyes Católicos. Tras los pasos de don Enrique Canario el último mencey de Icod», Revista de Historia Canaria, n. ${ }^{\circ}$ 185, (2003), p. 130.

4 De la Rosa Olivera, L. op. cit., pp. 12-13.

5 De la Rosa Olivera, L. op. cit. p. 3. 
su condición de christiano e libre e quito de toda servidumbre. Desde ese momento, no se tienen más noticias de él' .

De la suerte del último, el más famoso y más bello, tenemos noticias gracias a los Diarii del cronista veneciano Marin Sanudo. Su crónica relata que los monarcas castellanos lo donaron al embajador de Venecia, Francesco Capello, en noviembre de 1496 y que, unos meses después, viajó a la ciudad del Adriático. Fue exhibido como ejemplar exótico en la procesión del Corpus Christi de 1497, al lado del Doge Agostino Barbarigo, y luego fue enviado a vivir a Padua. Desde ese momento, se pierden todas las huellas de él.

La extrańa aventura de este mencey, desterrado de su reino en Tenerife para terminar sus días en Venecia, ha sido objeto de una publicación del profesor Rumeu de Armas $^{7}$ en 1975, y también ha inspirado dos novelas, una de María Rosa Alonso ${ }^{8}$ y la otra de Juan Manuel García Ramos ${ }^{9}$. Sin embargo, nuevos documentos encontrados en Venecia ponen en tela de juicio la reconstrucción de la vida del mencey sin nombre hecha por Rumeu de Armas y abren la posibilidad de que el rey de Tenerife, llegado a Venecia en junio de 1497, no fuera uno de los nueves menceyes llevados ante la Corte de los Reyes Católicos por Alonso de Lugo, sino, tal vez, uno de los caciques caníbales de las islas del Caribe traídos por Colón de regreso de su segundo viaje, en $1496^{10}$.

Para sustentar esta posibilidad, en el estudio se presentan dos nuevos documentos: la respuesta enviada por el Senado de Venecia a los Reyes Católicos para agradecerle el don y la deliberación original con la que el gobierno de la Serenissima decidió enviar al rey de Tenerife a Padua, documento este que solo se conocía a través de la síntesis hecha por Marin Sanudo en sus Diarii.

Se presentan también otras cuatro crónicas venecianas que refieren la llegada del «rey» a Venecia, signo de la importancia que el acontecimiento tuvo en la ciudad de la Laguna. Entre ellas se destacan los Annali de Domenico Malipiero, un cronista contemporáneo de los hechos que posiblemente tuvo la oportunidad de conocer personalmente a nuestro personaje.

Por último, se presentan tres obras de arte realizadas en Venecia entre 1497 y 1512 que, supuestamente, representan al rey de Tenerife. De particular interés para este tema es un fresco de la iglesia del Carmine en Padua en que aparece una cara con rasgos amerindios pintada en 1505.

${ }^{6}$ Gambín García, M.: «Un rey guanche en la corte de los Reyes Católicos. Tras los pasos de don Enrique Canario el último mencey de Icod», Revista de Historia Canaria, n. ${ }^{\circ}$ 185, (2003), pp. 125-126.

7 Rumeu de Armas, A.: La conquista de Tenerife 1494-1496, cap. xiv, pp. 314-333.

${ }^{8}$ Alonso, M. R.: La luz llega del este, La Laguna 1999.

${ }^{9}$ García Ramos, J.M.: Un guanche en Venecia, Baile del Sol (2014). La novela identifica el mencey sin nombre con Bencomo, que en realidad había muerto en la batalla de Acentejo.

${ }^{10}$ La circunstancia es relatada por Andrés Bernáldez, el Cura de los Palacios: el Almirante vino en Castilla en el mes de junio de 1496 (...) e truxo consigos algunos indios que antes que el de allí partiese habia prendido al Gran Cacique Caonaboa, en Bernáldez, A.: Crónica de los Reyes Católicos D. Fernando y D.a Isabel, Tomo I, Granada (1856), p. 331. 
Desafortunadamente, los nuevos documentos no ofrecen detalles suficientes como para determinar de forma definitiva la procedencia del rey. Sin embargo, abren la posibilidad de que el rey da Tenerife no fuera un mencey de esta isla, sino un rey caníbal proveniente del Nuevo Mundo.

\section{LOS DIARII DE MARIN SANUDO Y EL DECRETO DE LOS SAVI DI TERRAFERMA}

Los únicos documentos venecianos conocidos hasta hoy sobre la presencia del «rey de Tenerife» en Venecia eran los Diarii de Marin Sanudo (1466-1536) ${ }^{11}$. En esta monumental obra, que se compone de 58 volúmenes con más de 40000 páginas manuscritas y que tiene como protagonista a la ciudad de Venecia, Sanudo registra el día a día de una innumerable cantidad de información, desde noticias de política exterior hasta acontecimientos cotidianos, deliberaciones del gobierno y descripciones de las fiestas religiosas, novedades sobre las guerras e informes de crímenes. Los Diarii comienzan en 1496 y terminan en 1533, poco antes de la muerte del autor.

En su crónica, Sanudo le dedica tres pasajes. En el primero, fechado el 10 de junio de 1496, sintetiza un despacho del embajador en España, Cavalier Francesco Capello, y, después de haber hablado sobre la situación de la guerra entre la Liga antifrancesa y Francia, escribe:

Y dichos reyes de Espańa han donado al caballero Francesco Capello, nuestro embajador, con cargo que sea presentado a esta Señoría (de Venecia) un rey de corona, sarraceno, de aquellas islas recién encontradas, y parece que de dichos reyes hayan sido traídos 7 con estas últimas carabelas que han venido y el más famoso y más bello han querido donar a nuestra Señoría ${ }^{12}$.

En este relato Capello ofrece dos datos interesantes. En primer lugar, al hablar de unas últimas carabelas que llegan de aquellas islas recién encontradas puede referirse solo a las Islas Canarias y a las carabelas de Alonso de Lugo, porque Colón, de regreso de su segundo viaje, llegó a Cádiz al día siguiente, el 11 de junio.

11 De Marín Sanudo hemos consultado también De origine, situ et magistratibus urbis Venetae, ovvero, La citta di Venetia (1493-1530), sin encontrar alguna referencia al rey de Tenerife. Cisalpino-La Goliardica (1980).

12 Marín Sanudo: Diarii de 10 giugno 1496: «E ditti re di Spagna hano donato a Francesco Capelo cavalier orator nostro, con hordine che 'l sia apresentado a questa Signoria, un re di corona, saracino de quelli de l'isole che novamente sono state trovate, et par che de' dicti re ne siano stà menati 7 con queste ultime caravelle che sono venute, et il più famoso e più bello hano voluto donar a la Signoria nostra». 
En segundo lugar, Sanudo informa que los reyes llegados a España desde Tenerife eran siete, mientras que otros testimonios de la época afirman que eran nueve ${ }^{13}$.

El despacho original de Capello, del que habla Sanudo, se ha perdido en los incendios del Palacio Ducal de Venecia. Sin embargo, en los Archivi di Stato de Venecia ${ }^{14}$ se ha podido encontrar la respuesta enviada por la Serenissima a Capello. La carta, del 15 de julio de 1496, termina con una apostilla que aclara que el rey donado a Capello por los Reyes Católicos era un mencey de Tenerife ${ }^{15}$ :

13 En el juicio de residencia de Lope de Sosa a Alonso de Lugo en 1508 los testigos afirman que Alonso de Alcaraz, conquistador de Gran Canaria, «dixo que vió este ${ }^{\circ}$ quel dho Ad. se enbarcó en esta isla después de la a ver ganado para ir a su Alteza e levò consigo los dhos nueve Reyes y que oyó decir a los que venían de allá que avía. ido a la corte e los avía dado a sus Altezas». Diego Fernández Amarillo, lugarteniente del alguacil mayor Pedro de Vergara, «dixo que lo que sabe es que este $\mathrm{t}^{\circ}$ vido que partió el dho Ad. desta isla e llevó consigo los dhos nueve Reyes e se decía muy público quel dho Ad. los llevava para los presentar a sus Altezas e oyó decir lo contenido en la dha pregunta. Preguntado a quien... dixo que luego como se acavó de conquistar la isla lo oyó decir a muchas personas en general de cuyos nombres non se acuerda, e después acá». FraNCIsco Serrano «dixo que save que después que se ganó la dha isla el dho Ad. partió desta isla para la Corte e llevó consigo los dhos nueve reyes e queste t ${ }^{\circ}$ los vió partir e que lo demás contenido en la dha pregunta que lo non save. Oyó decir públicamente, en especial a Francisco de Corvalán e Mateo Viña e a Valdés que fueron con el dho Ad». Andrés Xuárez Gallinato, hijo de Pedro del Algaba y sobrino del Adelant, «dixo que sabe que llevó el dicho Ad. nueve reyes por que los vió en Castilla e oyó decir y es notorio que los llevó a Almaçán e los presentó a sus Altezas e se tuvieron por muy servidos dello». De la Rosa Olivera, L. y Serra Ràfols, E.: «El Adelantado D. Alonso de Lugo y su residencia por Lope de Sosa", Fontes Rerum Canariarum, 1949, p. 116. Confirma que son nueves también Núñez de la Peńa: «En el año de mil y cuatrocientos noventa y siete llevó el adelantado los nueve reyes a la presencia de los Católicos Reyes, que se holgaron de verlos y fueron bien recibidos y Sus Majestades les hicieron muchas mercedes». Y fray Felipe de la Gándara señala: «Venció y rindió nueve reyes, y con ellos triunfante volvió a España y los presentó a los Reyes que estaban en la villa, de Almazán, el año de mil cuatrocientos y noventa y seis» en "Armas y triunfos. Hechos heroicos de los hijos de Galicia», en Rumeu de Armas, A. op. cit., pp. 298-299. Antonio Rumeu de Armas, sin embargo, otorga más crédito al testimonio de Sanudo/Capello y piensa que los reyes llevados por Lugo a la Corte fueron siete, explicando la ausencia de los otros dos debido al suicidio del mencey de Taoro, Bentor, y por una posible enfermedad grave de otro de ellos. Ver Rumeu de Armas, A.: La conquista de Tenerife 1494-1496, Tenerife, 1975, p. 298.

14 Además de que en los Archivi di Stato de Venecia se ha verificado, sin éxito, la existencia de noticias en los siguientes fondos de los Archivi di Stato de Padua: Fondo ducali (b. 1), Libro verde (b. 3), Registro delle Ducali concernenti l'ufficio del Camerlengo (b. 76), Registro delle Ducali in materia di gravezze (b. 112), Ducali originali (b. 121).

${ }_{15}$ Archivi di Stato di Venezia: Deliberazione, Secreti, Registro (1496-1498) fl. 117-118: «Additio data per Collegium. Demum intelleximus de illo primario rege Tanarife vobis dono dato ab istis R. M.tibus in quo certe demonstrarunt magnitudinem amoris earum in nos. Volumus propterea ut forma verborum accomodata debeatis nostro nomine condignas gratias M.tibus suis, prout prudenter facturum non dubitamus». No se lee ningún agradecimiento por el «don» recibido en la carta enviada al nuevo embajador en España, Jacobo Contarini, el 22 de mayo de 1497, una semana después de la llegada de Capello y del rey a Venecia. ASVE Deliberazione, Secreti, Registro (14961498) fl. 288. 


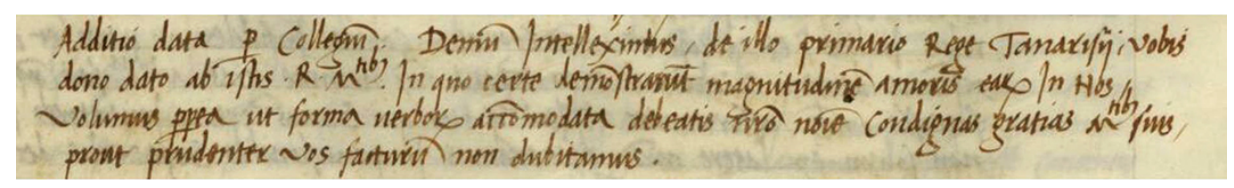

Foto 1. Archivio di Stato di Venezia: respuesta del Senado a Capello del 15 de julio de 1496.

Apostilla añadida por el Collegio (de Terraferma). Además, aprendimos (de la carta de Capello) de aquel importante Rey de Tanarife que vos fue donado por sus Majestades. Con este don por cierto demostraron la grandeza de su amor por nosotros. Queremos, por lo tanto, que vos dais las gracias a sus Majestades a nuestro nombre con palabras adecuadas, como sabiamente no dudamos que haréis.

Un año más tarde, el 17 de mayo de 1497, Sanudo vuelve a hablar del «rey de Tenerife» en los Diarii. Este segundo pasaje puede dividirse en dos partes. En la primera, Sanudo registra el regreso a Venecia del embajador Francesco Capello y de su compañero de viaje y repite las circunstancias que habían dado lugar a la aparición de este extraño personaje por las calles de la ciudad:

El día 17, el caballero Francesco Capelo, que había sido embajador en España, volvió con las galeras de la Berbería, al mando del capitán Piero Contarini, apodado el pelirrojo. Este trajo un rey de Canaria, con color de la piel como la de un sarraceno o, mejor dicho, gris como la ceniza, de aquellas islas nuevamente encontradas por el Rey de España, que le fue donado por dicho rey para que las ofreciese a la Señoría (de Venecia), como escribí más arriba (en los Diarii), cuando con sus cartas avisó de esta donación que le había hecho aquel rey. También llevó varios papagayos diferentes y de muchos colores $[. . .]^{16}$.

En la segunda parte de su crónica, Sanudo sintetiza el relato presentado por Capello frente al Senado y ofrece varios detalles del «rey de Tenerife», de sus hábitos y circunstancias de su captura, y relata los pormenores de cómo las autoridades venecianas llegaron a decidir sobre su futuro:

Y (cómo) había presentado dicho rey negro a la Señoría. Que era muy morigerado, pero no sabía hablar y sin embargo había sido bautizado. Sobre lo que se había que hacer con él se habló entre los Sabios del Consejo. Algunos querían donarlo al

16 SAnudo, Marín: Diarii 17 de mayo de 1497: "A dì 17, Francesco Capelo cavalier, stato ambasador in Spagna, ritornoe con le galie di Barbaria, capetanio Piero Contarini cognominato Rosso. Questo menoe con sì uno re saracino, o per dir meglio beretino di Canaria, di quelle ysole nuovamente trovate per il re di Spagna, el qual li fo donato da ditto re che lo apresentasse a la Signoria, come ho scripto di sopra, quando per sue lettere advisoe di questo presente li havia facto quel re. Etiam portoe alcuni papagali molto varii et de diversi collori». 
Marqués de Mantua y el ... de Junio el Consiglio dei Pregadi (Senado) se decidió que fuera a vivir a Padua, al palacio del Capitán, y que había que darle la cantidad de 5 ducados por su mantenimiento y 2 ducados por la persona que tenía que servirle. Y que se le comprasen ropajes, de vez en cuando, según sus necesidades. Esto se escribió por memoria del don enviado por el Rey y la Reina de España. Y decía que le parecía estar en el paraíso. Él, se decía (ut dicitur), tenía 2000 personas bajo su autoridad, y en su tierra comían carne humana, o sea de los ajusticiados, y junto con otros 6 reyes fueron llevados a Castilla en las carabelas, y fue gente de España la que tomó el dominio de dichas islas. Y se decía (ut dicitur) que, antes de ser sojuzgados, estos jefes se defendieron grandemente. Este rey caminó al frente de la procesión, al lado del Príncipe (Doge) el día del Corpus Domini (25 de mayo de 1497) y entró en Padua con el capitán Fantin da Pexaro el día 18 de junio $1497^{17}$.

En este segundo pasaje, se citan algunas informaciones acerca del gobierno de Venecia que merecen una aclaración:

- La Signoria de Venecia: por tratarse de un «rey» y de un don de reyes, el personaje fue presentado en primer lugar a la Signoria, que era la máxima autoridad de gobierno de la Serenissima. Este órgano estaba compuesto por el Doge, formalmente el jefe de Estado de la República de Venecia, seis consejeros ducales, que constituían el Minor Consiglio, y tres jueces de la Quarantia.

- Collegio dei Savi: la decisión de qué hacer con el rey fue delegada al Collegio dei Savi (Colegio de los Sabios), prácticamente el Consejo de Ministros de la Serenissima, que disponía en materia de política exterior y en asuntos militares y, por esta razón, recibía los relatos de los embajadores que regresaban de sus misiones, como era el caso de Francesco Capello.

- Francesco II Gonzaga, duque de Mantua, era el jefe de una de las familias nobles italianas que condicionaron la vida política italiana y europea en el tardío Medioevo y en el Renacimiento. La propuesta de donar el «rey» a Francesco II se justificaba por ser considerado el Gonzaga, en ese momento, el héroe de la batalla de Fornovo (1495), ya que había puesto fin a las aspiraciones del rey de Francia Carlo VIII de hacerse con el reino de Nápoles. Por esta

${ }^{17}$ SAnudo, Marín: Diarii 17 de mayo de 1497: «Et presentato dicto re negro a la Signoria. El qual era assà morigerato, ma non sapeva parlar, tamen era stà fatto batizar. Quello se ne dovesse far, tra li savii di collegio fue parlato. Alcuni el voleva mandar a donar al marchexe di Mantoa, et a dì ... zugno, per il consejo di pregadi fo preso parte che l'andasse ad habitar a Padoa in palazo dil capitano, al qual li fosse dato una caxa, et havesse di provisione al mexe ducati 5 di quella camera per farsi le spexe, et ducati 2 per chi starà con lui a servirlo. Et che fusse vestido, di tempo in tempo, come havia di bisogno. Questo fo scrito per memoria di tal presente mandato per quelli catholici re et regina di Spagna. El qual diceva li pareva esser in paradiso. Questo, ut dicitur, havia 2000 persone che manzava sotto di lui, et in lhoro paesi manzano carne humana, zoè zustisiada, et insieme con 6 altri re fono menati in Castiglia da le caravele et zente di Spagna che andono per tuor il dominio di dicte ysole. Et dicitur, prima fusse pigliati, questi capi fece gran difesa etc. Questo fo in precessione avanti el principe il zorno dil corpo di Cristo, et fé l'intrata a Padoa con Fantin da Pexaro capitano ivi andava, a dì 18 zugno 1497». 
victoria, en 1495, Venecia lo había nombrado comandante en jefe del ejército veneciano con el increíble sueldo de 44000 ducados anuales.

- La procesión del Corpus Christi era uno de los eventos públicos más importantes de la ciudad de Venecia. En ella participaban no solamente los personajes más notables del gobierno, sino también embajadores y representantes de todas las naciones que tenían relaciones comerciales con la ciudad, como se puede apreciar en la representación de la procesión del año $1496 \mathrm{del}$ pintor Gentile Bellini ${ }^{18}$. La aparición del rey de Tenerife al lado del Doge recuerda la presencia del rey de Gran Canaria, don Fernando Guanarteme, y su esposa, la princesa Guayarmina, al lado del rey don Fernando andando por las calles de Córdoba después de la conquista de la isla. Como escribe Rumeu de Armas, «relatan las crónicas que al Rey Católico le enorgullecía pasear a caballo por las calles de Córdoba, llevando a diestra y siniestra a los dos monarcas prisioneros ${ }^{19}$.

- Consiglio dei Pregadi: por último, el Consiglio dei Pregadi, uno de los órganos de gobierno más importantes del ordenamiento veneciano, se interesó de la suerte del «rey» y tomó la decisión de enviarlo a vivir a Padua, ciudad ubicada a unos 40 kilómetros de Venecia. El nombre Consiglio dei Pregadi, en castellano Rogados, se debía a la circunstancia de que, originariamente, se les rogaba a sus miembros ofrecer su consejo al Doge, máxima autoridad política de la ciudad. El nombre Senato se impuso recién en el siglo XIV.

En el tercer pasaje de los Diarii, Sanudo presenta un resumen de la decisión de otro órgano del gobierno de Venecia, los Savi di Terraferma ${ }^{20}$, del 2 de junio de 1497, en la que establece las condiciones de la estancia del «rey de Tenerife» en Padua:

Asíse decidió por el Consiglio dei Savi di Terraferma. El Serenísimo Rey de España entregó al caballero Francesco Capelo, nuestro embajador ante Su Majestad, el rey de Canaria cautivado en las Indias. Por lo tanto, se ha decidido que, habiendo sido conducido por el predicho embajador a esta ciudad, tenga que residir en Padua en casa del capitán ${ }^{21}$, que se ponga a su disposición una habitación amueblada, y 5

${ }^{18}$ El cuadro se encuentra en el Palazzo Ducal de Venecia.

19 Rumeu de Armas, A.: «Don Fernando Guanarteme y las princesas Guayarmina y Masequera en la corte de los Reyes Católicos», Revista de Historia Canaria, 1965-1966, p. 37. Desafortunadamente no se ha encontrado este episodio ni en la Crónica de los señores Reyes Católicos de Hernando del Pulgar ni en la Historia de los Reyes Católicos de Andrés Bernáldez.

${ }^{20}$ Los Savi de Terraferma (Sabios de Tierra Firme) era un organismo de cinco magistrados, elegidos por seis meses por el Senado, que estaba encargado de la supervisión de todos los territorios no metropolitanos bajo el control de Venecia, entre los cuales se encontraba la ciudad de Padua.

${ }^{21}$ Desafortunadamente al respecto no se ha encontrado ningún documento en Padua, ya que los actos de la Cancillería del Capitán de la ciudad empiezan en 1630. 
ducados al mes para su mantenimiento y que le sirvan dos criados que recibirán de la Cámara un ducado al mes. Y que al dicho rey se le compre ropaje etc. ${ }^{22}$.

Por suerte, además del relato de Sanudo, nos ha llegado también el documento original de esta deliberación, que se conserva todavía en los Archivi di Stato di Venezia:

Como es conocido por este Consejo (de los Savi di Terraferma), los serenísimos Reyes de España donaron al caballero Francesco Capello caballero, entonces nuestro embajador en la corte en representación de nuestra Signoria, el primero de los nombrados reyes de Canarias, cautivados por los capitanes se sus altezas, en signo de demonstración de la buena amistad entre sus altezas y la Signoria. Y siendo conveniente hacer en cambio demostración de gratitud por este don, sobre todo porque los otros príncipes que recibieron similares reyes inferiores a este han proveído a su necesaria comida y vestuario, lo mismo también hacemos:

Así se establece: que el dicho rey de Canaria sea enviado a Padua, y sea notificado y ordenado a nuestros gobernantes de allí que tienen inmediatamente que poner a su disposición en el Palacio del Capitán una habitación con todo lo necesario, y que por el mantenimiento suyo y de dos servidores, y de su habitación, tiene que recibir todos los meses, por toda la vida, cinco ducados al mes. Además, debe tener dos servidores para servirlo, con un sueldo de un ducado al mes cada uno.

Además, los supradichos gobernantes tienen que proveerle de vestimentas apropiadas de tiempo en tiempo, de acuerdo a lo que le parecerá necesario ${ }^{23}$.

22 Marín Sanudo: Diarii 2 de junio de 1497: «Die 2 Junii 1497 in rogatis. Fu posto per i savii dil consejo e terra ferma. Il serenissimo re di Spagna donoe a ser Francesco Capelo el cavalier, orator nostro apresso soa maestà, il re di Canaria preso in le Indie. Pertanto, sia preso che, essendo stà conduto per il prefato orator el ditto in questa cità, debbi star a Padoa in casa dil capitano, e li sia dato una camera fornita, e di provision ducati 5 al mese, et habbi con lui do famegii qualli habbino di danari di la camera duc. uno al mese. Et el ditto re sia vestio etc. $120-28-1$ Apar in libro $13^{\circ}$ parte terza a carte 3 ».

23 Archivi di Stato di Venezia, Senato, Deliberazioni, Terra. Registro (1497-1500) fl 005-R2 de junio de 1497: «Come è noto a questo conseglio, li serenissimi re de Spagna hano donado al nobel homo Francesco Capello cavalier, tunc ambassador nostro a sua maestà a nome della signoria nostra, el primo de li nominati re de Canaria, preso per li capitanii de le maestà sue, in segno de demonstration de la bona amicitia che intercede tra sue altezze e la signoria nostra. Et siando conveniente far de converso demostration de de gratitudine per il don suprascripto, attento maxime che li altri principi che hano avuto simeli re inferior a questo hano provisto convenientemente al vitto et vestito suo necessario e he a questo etiam nui provediamo. Però l'anderà parte: ch'el dicto re de Canaria sia mandado a Padoa, et sia scripto et comandado a li rectori nostri de lì che li debia immediate proveder en la corte del capitanio de una camera fornita de tute cose necessarie, et che per el vivir suo et de duo famegli, de li denari di quella camera nostra, haver devia de provision al mese et a raxon de mese, in vita sua, ducati cinque, et sia pagato de mese in mese. Preterea haver devia duo suoi famegli quali lo habia a servir, et haver debiano li dicti famegli ducati uno al mese per cadauno. Ulterior che li dicti rectori vestir el debino de tempo in tempo convenientemente, come a loro parerà». BERCHET, G.: Fonti italiane per la storia della scoperta del Nuovo Mondo (1892), p. 42. 


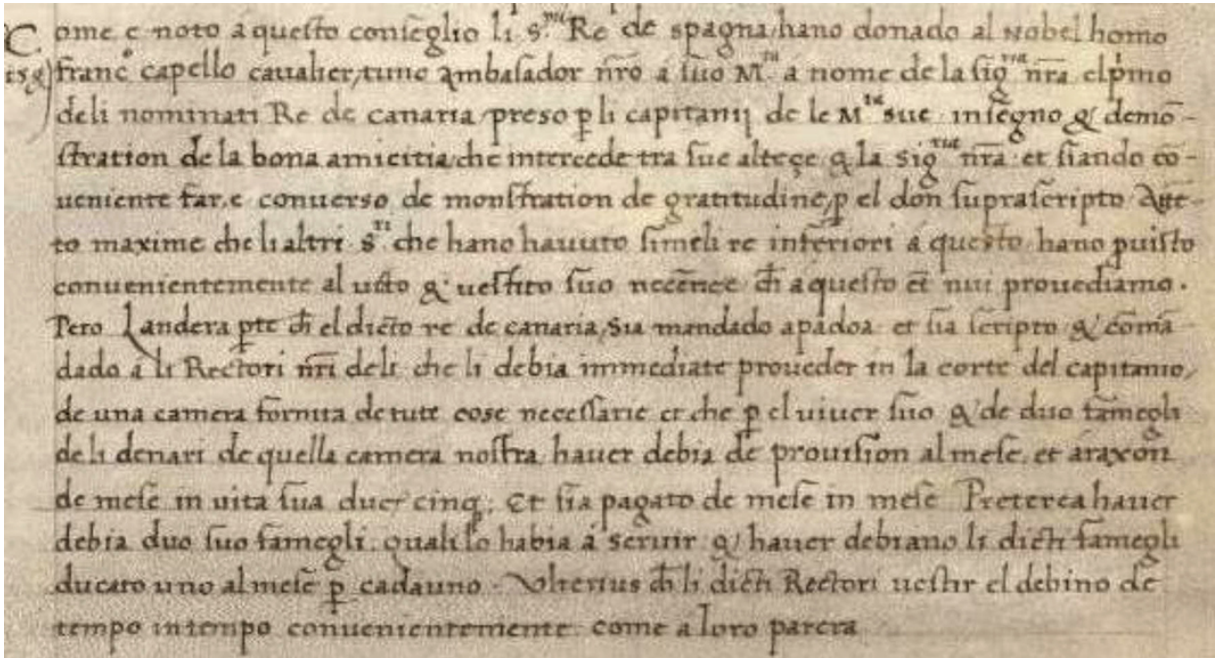

Foto 2. Archivio di Stato di Venezia.

El relato de los Savi di Terraferma es importante porque añade algunos elementos de interés al texto de Sanudo.

En primer lugar, denomina a nuestro personaje como re di Tenerife y no re di Canaria preso in le Indie, como hace Sanudo. El detalle es importante, pues certifica que Sanudo no se limitó a trascribir los documentos oficiales en los Diarii, sino tal vez los enriqueció con consideraciones personales.

En segundo lugar, el documento aclara la razón de por qué la Serenissima tenía tanto interés en este exótico personaje. Para una ciudad que tenía relaciones de igual a igual con el emperador, el papa, el sultán de Constantinopla y todos los reyes de Europa, un «rey salvaje» podía constituir una curiosidad de no mucha importancia. No así si el «rey» era el don de los Reyes de España, el más poderoso aliado de Venecia en la Liga antifrancesa, quien se oponía a las pretensiones del rey de Francia, Carlo VIII, de hacerse con el reino de Nápoles. No obstante, demostrar agradecimiento por el don no impidió que el gobierno de Venecia encontrara la forma más rápida y menos costosa de liberarse de este extraño e incómodo huésped sin ofender a los reales donantes. La decisión final de enviar al «rey de Tenerife» a Padua fue tomada en apenas cuatro días, y el vitalicio de cinco ducados mensuales para su mantenimiento era una cantidad suficiente para garantizar un honorable mantenimiento aunque no digno de un rey, si se considera que a Sanudo, para que siguiera escribiendo sus Diarii, la Serenissima le otorgaba un vitalicio de 150 ducados anuales ${ }^{24}$. 
En tercer lugar, de la crónica de Sanudo se desprende que, al llegar a Venecia, el estatus personal del «rey» no era el de un esclavo, sino el de un huésped al que había que tratar con respeto. Esta circunstancia podría indicar que la condición de christiano e libre e quito de toda servidumbre $e^{25}$ le fue reconocida a los menceyes desde el momento de su llegada a la corte de los Reyes Católicos, en 1496.

Por último, la referencia a los otros príncipes que recibieron similares reyes inferiores a este obliga a considerar la posibilidad de que, tal vez, el rey más famoso y bello, donado personalmente a Capello y no a la Serenissima ${ }^{26}$, no fue el único que fuera «donado» por los Reyes Católicos a personajes ilustres, quienes los tenían en sus cortes como una especie de ornamento o trofeo exótico ${ }^{27}$.

Algo similar había pasado pocos años antes, en 1493, con los indios traídos por Cristóbal Colón al regresar de su primer viaje a las Indias. Así lo relata un testigo ocular, el entonces paje Gonzalo Fernández de Oviedo:

Seis indios llegaron con el primero Almirante a la corte, a Barcelona, cuando he dicho; y ellos, de su propia voluntad, e consejados, pidieron el baptismo; e los Católicos Reyes, por su clemencia, se lo mandaron dar; e juntamente con Sus Altezas, el serenísimo príncipe don Juan, su primogénito y heredero, fueron los padrinos. Y a un indio, que era el más principal dellos, llamaron don Fernando de Aragón, el cual era natural desta isla Española, e pariente del rey o cacique Goacanagarí; e a otro llamaron don Juan de Castilla; e a los de demás se les dieron otros nombres, como ellos los pidieron o sus padrinos acordaron que se les diese, conforme a la Iglesia Católica. Mas a aquel segundo que se llamó don Juan de Castilla, quiso el

25 AGS, RGS, 4 de diciembre de 1500, en Gambín García, M.: «Un rey guanche en la corte de los Reyes Católicos. Tras los pasos de don Enrique Canario el último mencey de Icod», Revista de Historia Canaria, n. ${ }^{\circ}$ 185, (2003), p. 131.

${ }^{26}$ Como se verá más adelante, en la carta de nombramiento de Capello a Conde de la isla de Rosas o de los Canibales del 1 de septiembre de 1496 se escribe claramente donar a Usted (Capello) el más digno de los nueves reyes. En los Diarii de Sanudo se habla siempre del «rey» como de un don a la República, pues los regalos recibidos por los embajadores eran de propiedad de la Serenissima. Los embajadores tenían el derecho de comprarlos pagando una suma de dinero cuando los regalos eran de carácter personal. También el embajador Capello, por ejemplo, recompró parte de los regalos de los Reyes Católicos: «Et che li era stà donato do mulle et una vesta di restagno (paño) d'oro bellissima, la qual, justa il solito presentata a le raxon nuove, la recomproe per duc. 10 e s. 16» (cerca de 3000 maravedís). SAnudo: Diarii, 17 de mayo de 1497. Este "traje de paño de oro" no aparece entre los regalos recibidos por Capello, que comprendían, de acuerdo con los archivos de la Contaduría Mayor «dos fuentes de plata, valoradas en 92.027 maravedíes, que la reina Isabel "mandó tomar" de la recámara del obispo de Falencia Alfonso de Burgos para dar al embajador de Venecia, y por cuyo dorado hubo que pagar 16.830 maravedíes. El otro regalo consistió en dos copas de plata dorada, propiedad de la condesa de Haro, por las que se abonaron 25.687 maravedíes. A ello se vinieron a añadir dos muías con sus correspondientes guarniciones, adquiridas, el 10 de noviembre, por el tesorero Gonzalo de Baeza por precio de 40.911 maravedíes».

${ }_{27}$ Rumeu de Armas, A. op. cit. p. 309. 
príncipe para sí, y que quedase en su real casa, y que fuese muy bien tractado e mirado, como si fuera hijo de un caballero principal a quien tuviera mucho amor [... $]^{28}$.

Gracias a los documentos sabemos, por ejemplo, que también tuvo la misma suerte de ser un «don» el mencey de Icod, Belicar, quien, con el nombre de don Enrique Canario, probablemente fuera adscrito al séquito del príncipe Juan de Aragón, segundo hijo y heredero de los Reyes Católicos, don Fernando y dońa Isabel ${ }^{29}$, e ilegalmente vendido como esclavo después de la muerte del príncipe.

Una carta a Ercole d'Este duque de Ferrara, del 15 de septiembre de 1496 parecía haber aclarado la desafortunada suerte de otros dos menceyes. En ella se relata el hundimiento de la galera Chatania en el puerto de Génova, cuando volvía de Cádiz: y entre las otras cosas habia (en la galea) los dos hombres (...) que recién se habian encontrado en aquella isla desconocida, y habia caballos bereberes y mulas lindisimas y todos han muerto ${ }^{30}$.

En realidad, los dos hombres de la isla desconocida eran probablemente indios traídos por Colón en su segundo viaje y enviados al mercado de esclavos de Génova para su posterior venta ${ }^{31}$.

\section{LAS CRÓNICAS DE VENECIA}

En Venecia, tal vez más que en cualquier otra nación de Europa, floreció en el tardío Medioevo y en el Renacimiento el género literario llamado «crónicas», escritas para exaltar las glorias de la Serenissima, o el rol de una u otra familia noble, o simplemente para recopilar hechos cotidianos e informaciones útiles para el comercio. Las más de dos mil crónicas y anales que nos han llegado constituyen una fuente imprescindible para el conocimiento de la historia de Venecia.

${ }^{28}$ Fernándex de Oviedo, G.: Historia General y Natural de las Indias, Madrid, (2. $\left.{ }^{a} \mathrm{ed}.\right)$, I, cap. viI, p. 31, en Gambín García, M.: op. cit., p. 137.

${ }_{29}$ Gambín García, M.: op. cit., pp. 136-140.

30 Rangoni, F.M.: "Carta a Ercole Duca di Ferrara» en Fonti Italiane per la storia della scoperta del nuovo mondo, Parte III, vol. 1, 1892 p. 149. E «tra le altre fin i due homeni de quelli che scripsi a zorni passati a vostra excellencia che novamente erano stà ritrovati a quella ysola incognita, cavalli barberi e mule bellissime c'era che son tuti periti». Del acontecimiento hablan también Sanudo y Malipiero, sin referir de los dos indios: SANudo (13.9.1496): «In questi giorni, vene letere di Zenoa, come, a dì ditto, lì in Zenoa in porto, con bonaza, si era roto una nave di botte 2500 patron Francesco Catanio, la qual ritornava quel zorno di Spagna, overo di Cades, carga di zucari di Medera». Malipiero: La nave Cattanea, de 2,500 bote, che vegniva de Cales, cargha de zucari de Madera (erano casse 2,500); ogli, cuori et pani) sommersa in porto de Zenoa.

31 El patrón del barco Chatania era Francesco Cattaneo, oriundo de una familia noble de Génova, quien formaba parte de la colonia genovesa asentada en Cádiz. Cattaneo era amigo personal de Colón y había ayudado al almirante a desembarcar en Cádiz en junio de 1496. OTte, E.: Sevilla y sus mercaderes a fines de la Edad Media, 1996, p. 190. Almagí́, R.: Gli italiani primi esploratori dell'America, 1937, p. 155. 
Por tal motivo, en este estudio se ha intentado averiguar si la presencia del «rey de Tenerife» pudo haber dejado algún rastro en crónicas y documentos venecianos de la época ${ }^{32}$. No sin sorpresa se han encontrado cuatro crónicas que confirman la noticia ${ }^{33}$.

La primera referencia se encuentra en Stefano Magno (1499-1557), autor de la Cronaca Magno y de los Annali Veneti, que son consideradas como unas de las fuentes más importantes para el conocimiento de la historia veneciana en las dos últimas décadas del siglo xv. Apoyándonos en una crónica más tardía, la Storia documentata di Venezia de S. Romanin publicada en 1856, sabemos que Magno anotó más o menos en estos términos la llegada del «rey de Tenerife»:

El rey de Espańa donó a la República (de Venecia) un Rey de las Canarias que fue llevado a Venecia el 17 de mayo de 1497 por Francesco Capello y fue alojado en Padua ${ }^{34}$.

Una segunda y más amplia referencia se encuentra en la Istoria vinitiana $a^{35}$, escrita por el noble hombre veneciano cardenal Pietro Bembo (1470-1547), quien en 1530 fuera nombrado historiador oficial de la República de Venecia por el Senado. La obra se compone de 12 volúmenes que cubren la historia de Venecia desde 1487 hasta 1513 y ha sido escrita utilizando documentos oficiales de la época, hoy perdidos, como también los Diarii de Sanudo. En el texto Bembo así se describen los acontecimientos:

Habían los Reyes de Espańa en los meses anteriores enviado por medio de M. Francesco Capello embajador de la República (de Venecia) que volvía a casa, el Rey de las Islas Afortunadas, don que sin duda tenía que ser muy valorado porque esa tierra che se encuentra en el Océano Atlántico cerca di mil millas lejos de la tierra firme hacia el mediodía, por muchos siglos desconocida, por obra y diligencia de los Reyes de Espańa solamente ahora se ha vuelto a encontrar y, enviados trabajadores

${ }^{32}$ Del episodio se encuentra noticia, fuera de España y Venecia, en la Histoire Ecclesiastique del Abad Claude Fleury: "Quand les Espagnols se rendirent maîtres de cette isle, elle étoit gouvernée par un roi qu'ils firent sortir du pays: il passa à Venise où l'on fut fort surpris de la nouveauté $\&$ de la bisarrerie de sa figure, de ses habits, de son langage $\&$ de ses mœur». Abad Claude Fleury: Histoire Ecclesiastique, Paris 1760, vol. 24, p. 287. Fleury utiliza como fuente a Juan de Mariana: El Rey de aquella isla (Tenerife) traído a España, de alli le enviaron a Venecia en presente a aquella Señoría, de Mariana, J.: Historia general de España, libro xxvi cap. x.

${ }^{33}$ No se ha encontrado alguna referencia del «rey de Tenerife» en la cuarta de las grandes crónicas venecianas del siglo Xv, los Diarii di Girolamo Priuli. PrIULI, G.: «I diarii» in Raccolta degli storici italiani, tomo xxıv parte III. Tampoco en la Cronica di Venezia di Giovanni Tiepolo, fu Agostino patrizio veneto, Bologna (2013).

34 Romanin: Storia documentata di Venezia, Venezia, 1856, tomo v, p. 66, nota 1 (Cronaca Magno, t. IV, presso Cicogna). Desafortunadamente los dos manuscritos del Magno, que se encuentran respectivamente en la Biblioteca Marciana y en el Museo Correr de Venecia, son una recopilación de eventos, no siempre presentados en orden cronológico, y no ha sido posible encontrar la cita original.

35 Bемво, P.: Della historia vinitiana», Venezia 1552, libro Iv, pp. 44-45. La obra escrita en latín ha sido traducida pocos años después al italiano por el mismo Bembo. 
y jueces y sometida a su poder, se incorpora a todo el mundo conocido. Y este Rey fue hospedado por orden del Senado en Padua a expensas de las arcas públicas ${ }^{36}$.

El aspecto interesante de la crónica del Bembo, quien no era un simple cronista, sino uno de los literatos más influyentes de su época, es que no se limita a describir sintéticamente los hechos de la llegada de Capello. En ella se ofrecen también detalles de la conquista de las Islas Canarias, a las que localiza geográficamente mil millas lejos de la tierra firme. El error en la distancia no debe hacer pensar que Bembo confundiera las Canarias con las Indias recién descubiertas por Colón, pues en otro pasaje de su obra el autor nos informa que «en el ano de Venecia de 1701 (1492 a. D.) con tres navíos Colón fue a las Islas Afortunadas, que hoy en día se llaman Canarias, y desde ellas navegando por treinta y tres días hacia Occidente detrás del sol encontró seis islas».

Una tercera referencia es la transcripción de una carta de un embajador veneciano desconocido ${ }^{37}$, tal vez el mismo Capello, que se encuentra en los Archivi di Stato de Venecia. La carta, escrita aparentemente en 1497, señala que

este monarca donó a Capello el rey de las Islas Afortunadas, colocadas en el Océano Atlántico, cerca de mil millas lejos de la tierra firme, reencontradas en aquellos tiempos por Cristóbal Colon, era apodado rey de las Islas Afortunadas jovencito, el cual conducido por Capello a Venecia fue enviado a vivir en Padua, y con decreto del Senado del 2 de junio de 1497, se les asignaron 5 ducados al mes por vivir, y se ordenó a los regidores de esta ciudad de poner a su disposición una habitación en el palacio del capitán ${ }^{38}$.

La carta, que en varios aspectos recalca la crónica del Bembo, es la única que indica el 2 de junio de 1497 como fecha del decreto del Senado que enviaba el «rey» a Padua. Desafortunadamente, al no ser encontrado el original por haberse perdido, no se conoce su autor ni su fecha de redacción y, por lo tanto, no es posi-

36 Bembo, P. op. cit.: «Haveano i detti Re di Spagna ne mesi passati mandato per M. Francesco Cappello Ambasciatore della Repubblica che a casa ritornava, il Re delle Isole Fortunate, dono senza dubbio da dovere essere caro : perciò che quella contrada del sodo elemento, che è nell'oceano Athlantico, dintorno a mille migla dalla terra ferma lontana verso il mezzo dì, molti secoli sopra noi non conosciuta; per opera $\&$ diligenza de medesimi Re di spagna allhora solamente ritrovata $\&$ lavoratori \& magistrati mandativi, \& nella loro balia ridotta al rimanente del mondo saggiunge. Il quale Re fu fatto dal Senato nutrire \& governare in Padoua a spese del pubblico».

${ }^{37}$ La transcripción en italiano de la carta original se encuentra en una recopilación de despachos de embajadores venecianos realizada por el noble Pietro Gradenigo en el siglo XviI, probablemente en vista de la redacción de una crónica de Venecia. Desafortunadamente la copia de Gradenigo no indica el nombre del autor y es erróneamente fechada 25 de abril de 1495.

${ }^{38}$ Archivi di Stato di Venezia, Miscellanea cod. 74, c. 143: «Questo monarca donò al Capello il re dell'isole Fortunate, situate nell'Oceano Atlantico, circa mille miglia lontano dalla terra ferma, ritrovate in què tempi da Cristoforo Colombo, era detto re delle isole Fortunate fanciullo, ed avendolo il Capello condotto a Venezia, fu mandato ad abitar in Padova, e con decreto del Senato 2 giugno 1497, gli furono assegnati ducati 5 al mese per viver, ed ordinato a rettori di detta città di fornirgli una camera nel palazzo prefettizio», en BerCHET. op. cit., p. 41 nota 1. 
ble verificar la confiabilidad de la afirmación de que nuestro personaje era apodado rey de las Islas Afortunadas jovencito.

Estas tres crónicas, quizás por haber sido escritas años después de los acontecimientos, no aportan nada nuevo al texto de Sanudo y se limitan a confirmar la presencia del «rey de Tenerife» en Venecia en 1497. Sin embargo, se ha encontrado una cuarta crónica escrita por Domenico Malipiero (1445-1513), un historiador contemporáneo de los hechos, quien, al igual que Sanudo, podría haber tenido conocimiento directo o informaciones de primera mano del «rey». En sus Annali ${ }^{39}$ Malipiero relata que ${ }^{40}$

Francesco Capelo cavalier ha llegado de su embajada en Espańa y ha venido con las galeas de Berbería ${ }^{41}$; $y$ ha conducido prisionero un Rey de Canaria, que el Rey y la Reina de España han encargado de presentar a su nombre a la Señoría; y es uno de los cinco reyes prisioneros que han sido llevados con las carabelas que han ido a la conquista de las Canarias; y confiesa que no le disgusta la carne humana, máximamente de los enemigos; adora el sol; es de tez oscura (brun), entre el blanco y el negro. Se decidió de darle una casa en Padua a expensas de la Camera, y cinco ducados al mes por sus gastos, y dos para dos servidores.

Como se ve, esta crónica, al igual que la de Sanudo, añade el dato de que él confiesa que no aborrece comer carne humana, máximamente de los enemigos, detalle que contrasta con la hipótesis de un mencey guanche de Tenerife y hace pensar más bien en un cacique caníbal de las islas del Caribe de los que fueron traídos a España por Torres en 1494 y por el mismo Colón ya en 1496.

Rumeu de Armas ha justificado esta incongruencia con la total ignorancia sobre la geografía del Atlántico del embajador (Capello), del Senado (de Venecia), que lo admite como bueno, y de Sanudo, que recoge y divulga la noticia ${ }^{42}$; ignorancia que

39 Malipiero, D.: «Annali Veneti dal 1457 al 1500» in Archivio Storico Italiano, tomo viI, parte I, Firenze 1843, p. 487. Arch. di Stato in Venezia, Miscellanea, cod. 122, c. 143. «Francesco Capelo k. (cavalier) è zonto dalla so ambassaria de Spagna, et è vegnù con le galie di Barbaria; et ha conduto captivo un Re de Canaria, ch'el Re et Rezina de Spagna ghe ha consegnà de presentar per so nome a la Signoria; et è un de i cinque Re presoni, che ghe son stati conduti con le caravele che andete ala conquista delle Canarie; e confessa che 'l no abhorisse carne humana, massimamente de nemisi: l'adora 'l Sol; l'è de color brun, tra negro e bianco. L'è stà preso de far fornir a questo re una casa a Padoa de i denari della Camera, e de darghe cinque ducati al mese per spese, e due per due famigli».

40 De acuerdo con algunos autores los Annali de Malipiero en realidad serían la transcripción del tercer volumen, hoy perdido, de los Annali veneti que otro cronista de la época, Pietro Dolfin (1427-1506), empezó a escribir en 1487. Ver Neerfeld, C.: Historia per forma di diaria, Venezia, 2006 pp. 76-95.

${ }^{41}$ Malipiero confirma la llegada de Capello con las «galias de Barberia». Normalmente el recorrido más rápido para volver a Venecia desde Espańa era la ruta por mar desde Barcelona a Génova, que se cumplía en ocho días. Sin embargo, en noviembre de 1496 la situación en el mar Tirreno no era segura para la navegación. Por este motivo, Capello escogió la ruta más segura y larga ofrecida por la «muda» de Barbería, que anualmente conectaba Valencia a Venecia, tocando casi todos los puertos del Mediterráneo meridional en seis meses.

${ }^{42}$ Rumeu de Armas, A. op. cit. p. 319. 
habría hecho confundir a los cronistas las Islas Canarias con las Indias. Lo poco que sabemos del conocimiento que se tenía del Atlántico y del descubrimiento del Nuevo Mundo en la Venecia de 1497 no parece confirmar esta posibilidad.

Por cierto, los venecianos no tenían un gran interés en las Islas Canarias, pues no ofrecían mercaderías útiles para sus comercios, como las especias del Oriente. $\mathrm{Si}$ a finales del siglo XV está ampliamente testimoniada la presencia de mercaderes genoveses y florentinos involucrados sobre todo en el comercio del azúcar en las Islas Canarias, no pasa lo mismo con los venecianos. Sin embargo, Venecia tenía contactos regulares con la isla de Madera, de donde recibía azúcar, y sus galeras navegaban regularmente más allá de las columnas de Hércules con la muda de le Fian$d r e^{43}$, que la conectaba con un servicio regular a los puertos atlánticos de Portugal, Inglaterra y los Países Bajos.

Los venecianos tuvieron también algunos importantes navegantes atlánticos: Pietro Quirino, en 1431, quien después de haber tocado las Canarias, descubrió las Islas Färoëren en el mar del Norte; Alvise Cadamosto, en 1453, que exploró las costas de Senegal por cuenta del rey del Portugal y descubrió parte de las Islas de Cabo Verde; Giovanni Caboto, financiado en 1497 por el rey de Inglaterra, a quien se debe el descubrimiento del Labrador; y Antonio Pigafetta, quien, para la Corona de Castilla, acompañó a Magallanes en el primer viaje alrededor del mundo en 1503.

Tampoco era escaso el conocimiento que se tenía sobre la geografía del Atlántico en Venecia. Los cartógrafos venecianos eran, junto con los genoveses y los mallorquines, de los mejores de Europa, y las Islas Canarias aparecen en todos sus mapas, ya desde el mapa Pizzigagno de 1347.

Y si los cronistas podían tener alguna duda geografica, no podía suceder lo mismo con el embajador Capello, quien en pocos meses había visto llegar a la Corte de los Reyes católicos tanto a Alonso de Lugo, con los mencey canarios, como a Cristóbal Colón, con los caciques caribeños. Además, Capello volvía a Venecia con el título de Conde de la Isla de Rosas sive Cannivalie ${ }^{44}$, primer título de nobleza creado

${ }^{43} \mathrm{La}$ «muda» era un servicio de transporte regular organizado por el estado que conectaba de forma regular y en fechas preestablecidas a Venecia con los puertos de diferentes regiones. En el siglo XIV operaban siete diferentes «mudas»: de Siria (Cipro y Beirut), de Egipto (Alessandria y Beirut), de Tana y Romania (Constantinopla y mar Negro), del Trafego (Tunes y Alessandria de Egipto), de Barbaria (África del norte y España meridional), di Acque Morte (Marsella y Barcelona) y de Fiandre (Brujas, Londres y Southampton).

44 De la Torra, A.: Documentos sobre las relaciones internacionales de los Reyes Católicos 1495-1497, Barcelona (1956), p. 355. Cadenas y Vicent, V. de: «El condado de Rosas, título nobiliario indiano de 1496» en Hidalguía, n. 17 (1956) pp. 473-480. Francesco Capello utilizó el título de Comes de Rosas Canibaliae en su estancia en Rímini en 1499 como proveedor de la República de Venecia. En un codice malestiano nella biblioteca dell'Arsena, La Bibliofilia, anno xxx, dispensa 12, p. 60. Y firmaba en 1504-1505 como Comes de Rosis sus despachos desde Alemania cuando era embajador de Venecia en la Corte del emperador Maximiliano, en Valentinelli, G.: Regesta documentorum Germaniae historiam illustrantium (1866), p. 228 
por los reyes de España en relación con los territorios del Nuevo Mundo ${ }^{45}$. En el documento del 1 de septiembre de 1496 el rey D. Fernando, después de agradecer al embajador sus servicios, también le dicta unas clases de geografía atlántica que no podían dejarle a Capello ninguna duda acerca de la diferencia entre Canarias e Indias:

... decidimos, sometida a nuestro poder la isla de Tenerife, que es una de las más insignes entre las otras nuestras Islas Canarias, de donar a Usted el más digno de los nueves reyes, prisioneros por derecho de guerra, que desde la misma Tenerife nos han llevado [...].

En consecuencia, como sean muchas las islas del Atlántico en el mar Océano, comúnmente llamadas islas indianas, sometidas a nuestro poder por el comandante de nuestra flota Columbus, por nuestra propia decisión decretamos Vos conceder, decorar y honorar con los emblemas y el título de conde de la isla de la rosa o de los caníbales $[. . .]^{46}$.

En realidad, la posibilidad de una equivocación entre Canarias e Indias por parte de los venecianos podría tener algún fundamento, si se considera que en muchos mapas medievales aparecían dibujados en el Atlántico dos grupos de islas llamados Canarias. Las primeras correspondían al actual archipiélago canario y las otras eran islas imaginarias, tal vez el recuerdo de las Islas Afortunadas de los antiguos, que se ubicaron primero al lado de las Islas Británicas y después al oeste de las Canarias actuales. Incluso el geógrafo Domenico Silvestri, en su islario De insulis de finales del siglo xiv, hablaba todavía de la existencia de una Canaria atlántica y de una Canaria indiana ${ }^{47}$.

Los venecianos podrían también haberse confundido debido a los términos en los que estaba redactado el Tratado de Alçacobas-Toledo de $1480^{48}$, con el que los reyes D. Fernando y D. Isabel, con la intención de poner fin a las interferencias de la Corona de Portugal en el reino de Castilla, le quitaron a Alfonso V de Portugal el derecho de navegación en el Atlántico, con la excepción del ámbito de las Islas Canarias, a saber, Lançarote, Palma, Fuerteventura, la Gomera, el Fierro, la

45 Montt, L.L.: «Normas sobre la concesión de títulos en Castilla», en Hidalguía 1981 n. ${ }^{\circ} 166-167$, p. 634 , nota 12 .

46 Cadenas y vicent, V. op. cit.pp. 279-281: «(...). placuit nobis, subacta in deditionem nostram Tanarifae insula, que inter alias nostras Canarie insulas una ex prestantioribus annumeratur, unum ex novem regulis, iure belli captis, quos ex ipsa Tanarifae insula captivos nobis attulerunt, digniorem, vobis dono dare, (...). (...) Quapropter, cum plures sint insule Athlanticae, per Columbum, classis nostrae prefectum, in Oceano mari nostrae ditioni subactae, quae vulgariter insulae indianae vocantur, motu nostro proprio decrevimus insignibus et titulo comitis insulae de Rosa sive Cannivaliae vos decorare, extollere et honestare (...)».

${ }^{47}$ Gentile, S.: Firenze e la scoperta dell'America, Olschki Ed. Firenze, 1992. p. 74.

48 Giménez Fernández, M.: «América, Yslas de Canaria por ganar», Anuario de Estudios Atlánticos, n. ${ }^{\circ} 1$ (1955), pp. 309-336. Calvo González, J.: «Sobre derecho y geografías simbólicas: Notas para una isla simbólica», Derecho, n..$^{\circ}$, 2005. 
Graciosa, la Grant Canaria, Tenerife, e todas las otras yslas de Canaria, ganadas o por ganar, las quales fincan a los rreynos de Castilla (cláusula viII).

Cuando Cristóbal Colón propuso a los reyes la empresa de llegar a las costas orientales de Asia navegando hacia occidente, en principio los juristas no encontraron otra solución para superar las prohibiciones del Tratado, que le impedían a la reina de Castilla enviar súbditos o extranjeros a su servicio a través del océano, que interpretar de la forma más amplia posible la parte de la cláusula viII que atribuía a los Reyes Católicos todas las otras yslas de Canaria, ganadas o por ganar, sin especificar cuán lejos se podían encontrar en el océano.

Ciertamente, esta interpretación extensiva generó confusión en los contemporáneos: cuando Giuliano Dati publicó la transposición en verso de la carta de Colón a Santangel de 1493, en la que anunciaba el descubrimiento de las Indias, terminó su obra con las palabras Finita la storia della inventione delle nuove isole di Canaria indiana tracte da una pistole di Cristoforo Colombo ${ }^{49}$.

\section{EL REY «CANÍBAL» DE TENERIFE}

Como se ha visto, las crónicas venecianas dejan abierta la posibilidad de que la verdadera proveniencia del «rey de Tenerife» no fuera las Islas Canarias, sino las islas del Caribe. Para intentar solucionar tal problema, se han analizado las pocas informaciones que ofrecen las crónicas acerca del «rey» con el fin de verificar su compatibilidad con la proveniencia de uno o del otro lado del Atlántico; y en particular se han evaluado las creencias religiosas del «rey», el número de sus hombres de pelea, su condición de caníbal y el color de su piel.

La primera información analizada es la afirmación de Malipiero de que el «rey» adora al sol. Esta creencia religiosa se condice perfectamente con la hipótesis de que el mencey provenía de las Islas Canarias, ya que grabados rupestres y crónicas de la época certifican que en Canarias existía algún tipo de culto a los astros y en especial al sol ${ }^{50}$. En uno de los primeros documentos conocidos que habla de los canarios, la bula papal $A d$ hoc semper de 1369, se autoriza el envío de religiosos a las Islas Canarias para iluminar con la luz del Evangelio aquellos pueblos que vivian en la superstición de los astros ... solo adoran el Sol y la Luna ${ }^{51}$. En la misma línea se expresan las primeras crónicas: para el veneciano Alvise da Cadamosto (1455) unos ado-

49 DAti, G.: Isole trovate nuovamente per el Re di Spagna», Firenze, 26 Ottobre 1492.

50 Tejera Gaspar, J.: «La religión en las culturas prehistóricas de las Islas Canarias», Zephyrus: Revista de Prehistoria y Arqueología (1990), pp. 235-242.

51 Papa Urbano V: Bula ad hoc Semper en Quartapelle, A. 400 años de crónicas de las Islas Canarias, Le Canarien Ediciones (2015), p. 60: «solem lunam adorantes». 
ran al sol, otros a la luna y otros a los planetas ${ }^{52}$ y para Pedro da Sintra (1482) adoran al sol como a un dios ${ }^{53}$.

Menos claras son las creencias religiosas de los pueblos caribeños. Por cierto, los taínos de la isla de la Hispaniola tenían cierta fe y conocimiento de un verdadero y solo Dios ${ }^{54}$ y sin embargo no parece que profesaran un culto a los astros o que adorasen al sol, como relatan las primeras crónicas, empezando por la Relación acerca de las antigüedades de los indios de fray Ramon Pane (1496) ${ }^{55}$ y como confirman Pedro Martir de Angleria ${ }^{56}$ y De las Casas ${ }^{57}$.

La segunda información ofrecida por los cronistas venecianos es el número de personas que dependían del «rey». Sanudo informa que habia 2000 personas bajo su autoridad (que manzava sotto di lui), número que podría parecer pequeño para un cacique del Caribe, lugar en el que vivían varios millones de personas. En realidad, la organización social de los indios se fundaba en pequeñas aldeas en las que los lazos entre los individuos se establecían por relaciones consanguíneas, y que raramente superaban los tres mil individuos ${ }^{58}$. El número no parece exagerado tampoco para uno de los menceyes de una isla como Tenerife. De acuerdo con Cadamosto, la población de Tenerife, a mediados del siglo xv, era de quince mil almas ${ }^{59}$, para Diogo Gomes da Sintra eran $23000^{60}$, y Eanes de Azurara escribe que en ella moran 6000 hombres de pelea ${ }^{61}$.

El tercer aspecto analizado es el tema de canibalismo al que se refiere Sanudo cuando escribe que ut dicitur en el país del rey-caníbal comen carne humana, o sea de los ajusticiados; o Malipiero, para quien el «rey» "confiesa que no le disgusta la carne humana, máximamente la de los enemigos». Es de toda evidencia que estos dos relatos representarían, por sí solos, la prueba definitiva del origen caribeńo del «rey», ya que los aborígenes canarios no practicaron ninguna forma de antropofagia mientras que, para los pueblos del Caribe, el canibalismo representa un mito etnográfico $^{62}$, el del indio salvaje comedor de carne humana, el caníbal.

p. 113.

52 Alise da Cadamost: «Paesi nuovamente ritrovati...», en Quartapelle, A. op. cit., p. 107.

53 Gomes da Sintra, D.: «El descubrimiento de Guinea», en Quartapelle, A. op. cit.,

${ }^{54}$ De las Casas: Apologética historia, volumen I, capítulo CXX.

55 Fray Ramon Pane: Relación acerca de las antigüedades de los indios.

${ }^{56}$ Angleria, Pedro Martir de: Década, I, lib. XI, cap. IV y viI.

57 De las Casas: Apologética.

58 Cassà, R.: «Los indios de las Antillas». Collección Pueblos y Lenguas Indígenas n. ${ }^{\circ} 10$ (1995) p. 89.

59 Cadamosto, A. op. cit., en Quartapelle, A. op. cit., p. 106.

${ }^{60}$ Gomes da Sintra, D. op. cit., en Quartapelle, A. op. cit., p. 113.

${ }^{61}$ Eanes de Azurara: «Crónica del descubrimiento y conquista de Guinea», en Quartapelle, A. op. cit., p. 93. Aznar Vallejo, E.: La integración de las Islas Canarias en la Corona de Castilla (1478-1526), Tenerife 1983, p. 151 y nota 16 p. 169.

${ }^{62}$ El primero en difundir este mito fue Colón, que, en su Diario de a bordo del primer viaje, introduce la distinción entre indios «buenos» e indios «malos», contraponiendo los arawak, hospitales, dóciles, miedosos, que no conocen las armas, fáciles de subyugar, a los caribes, salvajes, guerreros, crueles y antropófagos. En un primer momento, al hacer esta distinción Colón fue condicio- 
Para verificar la confiabilidad de los relatos, se ha verificado el conocimiento que se tenía de la antropofagia en la Venecia de 1497. Ciertamente, la figura del antropófago era un tema recurrente en los relatos de los grandes viajeros venecianos al Asia de los siglos XIII y XIV ${ }^{63}$ :

- Giovanni da Pian del Carpine ${ }^{64}$ escribe de los mongoles que en caso de necesidad comen carne humana;

- Marco Polo ${ }^{65}$ de los habitantes de la isla de Giava, que los de las montañas son como bestias porque comen carne de hombre. Y, hablando de la isla de Zipanu (Cipango), que cuando alguien de esta isla hace prisionero a un hombre que no puede pagar su rescate, invita a sus parientes y amigos, y lo cocinan y se lo dan de comer; y dicen que es la mejor carne que se pueda comer.

- Odorico da Pordenone ${ }^{66}$ de los habitantes de la isla de Lamori, que esta gente es muy maligna y criminal: comen también carne humana, como nosotros comemos la carne de res. Y en otra parte, que a estas tierras llegan mercaderes desde muy lejos y llevan niños para venderlos a los infieles que los matan y los devoran;

- Jehan di Mandeville ${ }^{67}$ (1356), quien copia el texto de Odorico acerca del comercio de los niños en Sumatra y comenta que si son gordos, los comen inmediatamente, $y$ si son magros los ponen a engordar.

Como se puede apreciar leyendo estos relatos, una práctica tan inmunda como la de comer la carne de otro ser humano a los ojos del hombre medieval se podía explicar solo por dos motivos:

nado por sus informantes arawak, quienes eran tradicionalmente hostiles a los caribes. Luego, como subrayan muchos historiadores, tomaron probablemente más relevancia consideraciones económicas; en primer lugar, la necesidad de encontrar mano de obra para los mercados de Espańa y de las colonias, especialmente después que la Reyna Isabela en 1503 estableció que solo los habitantes del Nuevo Mundo que eran "caníbales» podían ser esclavizados.

${ }_{63}$ De Feво, M.: «Forme dell'antropofagia in alcuni testi medioevali», in Letteratura, alterità, dialogicità. Studi in onore di Antonio Pioletti, Le Forme e la storia, n.s. viII, 2015, 1, pp. 327-339.

${ }_{64}$ Pian del Carpine, Giovanni di: Storia dei Mongoli, cap. Iv: in necessitate carnem humanam manducant.

${ }^{65}$ Polo, M.: Il libro delle meraviglie. Quelli delle montagne sono come bestie, ch'egli mangiano carne d'uomo (....). Cap. 141. Della Piccola Isola Di Giava: «Quando alcun di quest'isola prende qualche uomo che non si possa ricompensare, convita suoi parenti e compagni, e fanno 'l cuocere e dàllo a mangiare a costoro; e dicono chè la miglior carne che si mangi». Cap. 155: Come sono gli uomini di quest' isola di Zipanu.

${ }^{66}$ Pordenone, Odorico da: «Relatio». Cap. xvi de los abitantes de la isla de Lamori: «Hec gens est valde pestifera et nequam: carnes enim humanas comedunt, sicut hic comedimus carnes manzinas»; cap. XVII "Ad hanc terram accedunt mercatores de partibus longinquis infantes portantes quos illic vendunt infidelibus, qui ipsos mactant, devorant et consummunt».

${ }^{67}$ Mandeville, Jean di: Livre des merveilles du monde. Parlando del commercio di bambini gestito dai mercanti che approdano a Lamory, l'autore puntualizza che: Sils sount crassez, ils les mangent tantost, et sils sont megres ils les funt encrasser. 
- En el canibalismo "por hambre» ${ }^{68}$ la carne humana representaba la única alternativa frente a la escasez de otros alimentos, era una «necesidad», práctica conocida también en el Occidente cristiano cuando el hambre, consecuencia de carestías y asedios, hacia desvanecer el confín entre alimentos mundus e immundus. Como narra don Hernando Colón, en el viaje de regreso del almirante en 1496, la escasez de alimentos llegó a tal punto que muchos (de los tripulantes), como caribes, querian comerse a los indios que llevaban ${ }^{69}$.

- En el canibalismo "por vicio», el más execrable, la carne humana se transformaba en un manjar delicioso y por eso las víctimas se comerciaban, se criaban y engordaban, se castraban, incluso se prefería a los niños o jovencitos, pues su carne era más tierna y suculenta.

Este dualismo entre canibalismo "por hambre» o canibalismo "por vicio» no está presente en las crónicas venecianas. Al referir que las víctimas del canibalismo son ajusticiados o enemigos, Sanudo y Malipiero podrían aludir, tal vez, a una tercera forma de antropofagia, la antropofagia como acto ritual por motivaciones religiosas, práctica típica de sociedades con una cultura simbólica que atribuye particulares significados a la vida y a la continuidad del ser humano más allá de la muerte. En el canibalismo ritual no se come al otro por hambre o por gusto, sino después de haberlo ofertado a los dioses o para apropiarse de sus poderes y de sus virtudes: se come el corazón del enemigo para apoderarse de su coraje, el hígado para su fuerza vital, el cerebro para transferir el alma al que lo come.

Sin embargo, el canibalismo ritual se daría a conocer en Europa solo después de la conquista de México y la descripción de los sacrificios humanos practicada por los aztecas ${ }^{70}$. En 1497, el único relato conocido del Nuevo Mundo en Venecia era la carta de Colón a mosén Luis de Santangel, escribano y tesorero de la Reyna

\footnotetext{
${ }^{68}$ Jareguis, C.A.: Canibalia, Ed. ETC, 2008.

${ }^{69}$ Colón, H.: Manuscrito del Libro Copiador de Colón». Cap. LXIv, p. 233, en León Gue-
} RRERo, Montserrat: El segundo viaje colombino, Universidad de Valladolid (2000) p. 532.

${ }^{70}$ Los otros documentos que relatan de los caníbales escritos entre 1492 y 1495 , como el diario de a bordo del primer viaje y varias cartas, se conocieron solo después de 1497. Gianbattista Strozzi (1494): «Comen carne humana de muchachos y hombres castrados que tienen como capones a engordar como capones y despues los comen. Estos indios se llaman Canibali. In estas islas no hay animales (...) ni trigo, ni vino y viven de llervas y frutas y carne humana». Giovanni de Bardi (1494): «Item portano ditte caravelle 26 indiani de diverse isole et lingue // vero è che sono quasi de una medesima statura fra quali ve n'è // 3 canabali, de quelli che vivono e mangiano carne humana». Michele da Cuneo (1495): «Los caníbales cuando logran apoderarse de los indios los comen como nosotros los cabritos, y dicen que la carne del varón es mejor que la de la mujer. Son muy codiciosos de la carne humana, y para poderla comer suelen estar lejos de sus pueblos seis, ocho y diez años antes de volver y se quedan en las islas donde llegan hasta despoblarlas». Simone dal Verde (1494): "Quello che io credo per detto di tutti, egli è certo che costoro mangiano la carne humana; e così lo dicon gli abitanti di quelle altre isole». En Morales Padrón, F.: Primeras cartas sobre América (14931503), Sevilla (1990). pp. 103-175. 
Isabel y amigo de Colón, fechada el 4 de marzo de $1493^{71}$, en la que sin mayores detalles se lee que en las Indias hay una isla poblada de una gente que tienen en todas las islas por muy feroces, los cuales comen carne viva (humana) ${ }^{72}$. Por lo tanto, resulta difícil explicar cómo los dos cronistas pudieron tener información sobre el canibalismo ritual, si es que en este sentido se puedan interpretar las palabras de Sanudo y Malipiero, si no fue directamente de un cacique del Caribe ${ }^{73}$.

Por último, se ha verificado la afirmación de Sanudo que describe al «rey» como negro y también con el color de la piel como la de un sarraceno ${ }^{74}$ o, mejor dicho, beretino di Canaria, término traducido por Rumeu de Armas como infiel o bárbaro. En realidad, en dialecto veneciano beretino quiere decir de piel morena o gris como la ceniza ${ }^{75}$, característica confirmada también por Malipiero, quien lo describe como de tez oscura, entre negro y blanco ${ }^{76}$.

Esta descripción de la piel del «rey» aparentemente se adapta tanto a los habitantes de las Islas Canarias como a los indios caribeños. En su diario de a bordo del primer viaje Colón relata que los indios guanahani de la isla de Hispaniola son de la color de los canarios, ni negros ni blanco ${ }^{77}$.

Sin embargo, lo que Colón no podía saber es que la tez negruzca ${ }^{78}$ de los dos grupos étnicos tenía motivaciones totalmente diferentes: mientras que los indios

${ }^{71}$ La carta de Colón tuvo una inmediata difusión y se transformó en un best-seller de la época. En pocos meses, salieron de las imprentas de todos los países de Europa más de once ediciones en varios idiomas.

72 Malipiero en los Annali en el ano de 1493 así sintetiza la carta de Colón: La Isola que $i$ chiama Santa Maria, ha zente simele a l'altra zente; se no che le usa i caveli longhissimi e manzan carne humana, e va robando $i$ homeni per le altre isole.

73 Por cierto, en aquel 1497, la existencia de los antropófagos del otro lado del Atlántico no había interesado demasiado los embajadores de las cortes italianas, al considerar que al relatar acerca de las hazañas de Colón en ningún documento anterior al siglo Xvi se hace mención a la existencia de los caníbales.

${ }^{74} \mathrm{El}$ término «saracino» (sarraceno), utilizado por Sanudo, indica un color de la piel que tiende al negro. Scarabelli, L.: Vocabolario universale della lingua italiana, Milano (1878) vol. viI, p. 150.

${ }^{75}$ La correcta traducción del término berettino es gris o del color de las cenizas en Boerio, G.: Dizionario del dialetto veneziano di Giuseppe Boerio, Venezia, 1856, p. 76.

${ }^{76}$ La palabra utilizada por Malipiero es «brun», que quiere decir obscuro y negruzco. Boerio, G.: Dizionario del dialetto veneziano di Giuseppe Boerio, Venezia, 1856, p. 102.

77 Colón, C.: Diario de a bordo del 12 de octubre de 1492. Colón confirma esta observación acerca de la similitud del color de la piel de los canarios y de los caribeńos también el 13 de octubre: y ellos ninguno prieto, salvo de la color de los canarios, ni se debe esperar otra cosa, pues está esteoueste con la isla del Hierro, en Canaria, so una linea; el 6 de noviembre escribe: $y$ son ellas [las mujeres], de muy buen acatamiento, ni muy negras, salvo menos que canarias, en Quartapelle, A. op. cit., pp. 134-135.

${ }^{78}$ En la actualidad se sabe que el color de la pigmentación de la piel refleja la cantidad de melanina situada en las capas de la epidermis. Se sabe también que la cantidad de melanina está en función de la luminosidad ambiental y varía con la latitud. En el hombre se traduce en variaciones graduales, continuas, intermedias entre los dos extremos, blanco con muy poca melanina, como en los caucásicos, y negro con mucha melanina, como en los negroides o las poblaciones intertropicales de Asia (India meridional y Sri Lanka), y Oceanía (Australia y Melanesia). Tenemos también una idea del tiempo que es necesario para que una población se adapte a estas condiciones del medio 
del Caribe eran amerindios y el color moreno de la piel era una característica genética y permanente, no diferente de lo que pasa con las poblaciones negroides o las indotropicales de Asia, los aborígenes de Tenerife eran mediterranoides de tez clara y el color bronceado de la piel se debía solo a un aumento temporal de la pigmentación de la piel por la exposición al sol, como confirman las crónicas de la época que indican que solo los habitantes del sur de la isla, donde hay más sol, eran morenos, mientras que lo del norte eran blancos:

- Edmund Scory $(1526)^{79}$ :

Los naturales que habitaban en la banda sur de la isla eran del color de la aceituna, pero los que vivían en la banda del norte eran rubios, especialmente las mujeres, y tenían el pelo liso y brillante.

- Alonso de Espinosa $(1594)^{80}$ :

Es esta gente (los de la banda del sur) de color algo tostada y morena, agora sea por traer este color de generación, agora sea por ser la tierra algo cálida y tostarlos el sol, por andar casi desnudos, como andaban. Más los de la banda del Norte eran blancos, y las mujeres hermosas y rubias y de lindos cabellos.

- Abreu Galindo (1632) ${ }^{81}$ :

A los naturales de esta isla llaman guanches los que la conquistaron; era gente de mediana estatura. Los de la banda del sur son muy morenos, y los de la banda del norte son blancos y rubios en cuerpo y cabellos.

- Juan Núñez de la Peña $(1666)^{82}$ :

Los que habitaban a la banda del Sur, eran de color algo tostada y morena, y los de la banda de Norte eran blancos y rubios, como hoy se experimenta en los que nacen y se crían de las partes de Guimar, Arico, Chasna y sus términos que son al Sur algo morenos, de color trigueños, y los que nacen en Taganana, y sus términos que es al Norte, blancos y rubios.

ambiente modificando su DNA. Así, los paleosiberianos, que han invadido América entre -30 000 y -10000 ańos, se han adaptado desde milenios al nuevo ambiente en las zonas tropicales de Amazonia y han adquiridos pieles más oscuras, mientras que los que viven en las zonas árticas o en la Patagonia tiene una tez todavía clara. Chaline, J.: Del simio al hombre, Ahal, 1994, p. 95.

79 SCORY, Edmund: «Extracts taken out of the Observations of the Right Worshipfull Sir Edmond Scory», en Quartapelle, A. op. cit., p. 171.

${ }^{80}$ Espinosa, Alonso de: Historia de Nuestra Señoras de Candelaria, en Quartapelle, A. op. cit., p. 340.

${ }^{81}$ Abreu Galindo: «Historia de la conquista de las siete islas de Gran Canaria», en QuarTAPelle, A. op. cit., p. 428.

82 NúNé de la Peña, J.: "Conquista y antigüedades de la isla de la Gran Canaria», en Quartapelle, A. op. cit., p. 484. 
Los guanches son medianos de cuerpo los de Taoro, que es hacia la parte del norte son blancos y rubios de cavellos; los de Adexe a la del sur son prietos, y cavello negro (...).

Que la tez morena de los habitantes del sur de la isla fuese una característica temporal y no genética, como en el caso de los indios del Caribe, lo confirma Vieira y Clavijo (1700) al indicar que asumían el mismo color tostado también los españoles recién llegados a la isla:

si bien los guanches que habitaban hacia las partes meridionales de la isla eran de una tez bastantemente tostada, como lo son en el día cuantos españoles moran en ellas, no por eso dejaban de ser blancos, rubios y de buena presencia los que vivían en los distritos del Norte ${ }^{84}$.

Es de toda evidencia que las descripciones de Sanudo y Malipiero de un «rey de Tenerife» beretino y de tez obscura contrasta con la hipótesis de un mencey procedente de Tenerife. Si el color negruzco de los habitantes del sur de Tenerife era una característica no genética, sino la pigmentación temporal de la piel que experimenta cualquier mediterranoide que se expone por un tiempo a los rayos solares, es evidente que después de más de un año de la salida de Tenerife, la tez tostada del «rey» tenía que haber desaparecido para dejar espacio otra vez a su piel blanca.

Por el contrario, el color negruzco se corresponde con la descripción que nos han dejado todos los cronistas de la conquista que, al hablar de los indios caribeños, escriben:

ni son negros como en Guinea, no son tan negros como los etíopes, no negros, salvo más blancos que otros que haya visto en las Indias $\left(\right.$ Colón ${ }^{85}$; son de tez obscura (Coma); son pardos (Vaz de Caminha) ${ }^{86}$; son de color membrillo (Oviedo) ${ }^{87}$; son trigueños o pardos (Gumilla) ${ }^{88}$.

${ }^{83}$ Arias Marín de Cubas, Tomás: «Historia de las siete islas de Canaria», en QuartaPELLE, A. op. cit., p. 541.

${ }^{84}$ Viera y Clavijo, J.: Noticias de la Historia General de las Islas Canarias. Sta. Cruz de Tenerife, 1950, t. I. p. 119. El poeta Antonio de Viana (1604) imagina a Bencomo, mencey de Taoro, de color moreno, su hija, la princessa Dácil, de blanco cuello, y Guacimara, hija del mencey de Anaga, con derecho y alto cuello en color nieve (...) los pechos albos. VIANA, A. de: Antigüedades de las islas Afortunadas de la Gran Canaria, La Laguna (1905), pp. 73, 130 y 93.

${ }^{85}$ Colón, C.: Relaciones y cartas de Cristobal Colón, Madrid 1892. Carta a Luis de Santangel, p. 191 y Carta a Rafael Sánchez, p. 202. Relación del tercer viaje, p. 286. En otras cartas Colón describe los indígenas de forma diferente, en el Relato del primer viaje dice: harto blancos que si anduvieses y guardases del sol y del aire serían casi tan blancos como en España (...), p. 103. vieron dos mujeres mozas tan blancas como podian ser en España. p. 99.

${ }^{86}$ Morales Padrón, F. op. cit., Coma, G. p. 190; Vaz de Caminha, p. 232.

87 Fernández de Oviedo, op. cit., p. 31.

${ }^{88}$ Padre Gumilla, J.: "El Orinoco ilustrado». 
También se ha verificado el color de la piel de los esclavos canarios vendidos en el siglo $\mathrm{xv}$, característica que aparece indicada en los contratos de venta en la mayoría de los casos, cuando se especificaba el color de la piel, se indicaba "canario blanco» ${ }^{89}$.

\section{EL «REY DE TENERIFE» EN EL ARTE ${ }^{90}$}

Además de las crónicas, se ha intentado averiguar si un personaje pintoresco como el «rey de Tenerife» pudiera haber dejado algún rastro en las representaciones artísticas de Venecia.

En primer lugar, se han analizado los Do Mori ${ }^{91}$ (dos moros), las dos estatuas de bronce colocadas encima de la Torre dell'Orologio, en plaza San Marcos de Venecia, que la cultura popular canaria ${ }^{92}$ considera la representación de dos guanches en su característico tamarco, una prenda hecha de piel de cordero, a la manera de un camisón, sin pliegues, ni cuello, ni mangas, cosida con tiras de la misma clase de piel ${ }^{93}$.

A pesar del parecido con los antiguos guanches, los Do Mori en realidad no pueden representar al «rey de Tenerife» porque las dos imponentes estatuas de bronce, de 2,60 metros de altura y 3 toneladas de peso ${ }^{94}$, fueron fundidas en el Arsenale de Venecia por Ambrogio dall'Ancore el 27 octubre de 1497, tan solo cinco meses después de la aparición del «rey» en las calles de la Serenissima.

Otra posible imagen del «rey» se encontraba pintada, supuestamente, en el retrato de Colón realizado por el pintor veneciano Lorenzo Lotto en 1512, redescu-

89 Ortega Villoslada: «De Mallorca al Atlántico bajo la dinastía privativa», Mramegh, 21 (2011), p. 20, nota 31 de Rumeu de Armas, A.: La politica indigenista de Isabel la Católica, Valladolid (1969) pp. 249, 252 y 406. Franco Silva, A.: «El esclavo canario en el mercado de Sevilla a fines de la Edad Media». Actas del XIII Coloquio de Historia Canario-Americana, p. 58. Rumeu DE Armas, A.: «La conquista de Tenerife 1494-1496», p. 202. El viajero alemán Jeronimo Munzer describe a unos esclavos canarios recién llegados a Valencia en 1494 como hombres morenos, pero no como los negros en Viaje por España y Portugal. Madrid (1951) p. 17. En el mercado de los esclavos de Génova a la mitad del siglo xv, donde las mujeres eran valoradas en función del color de la piel, las canarias recién traídas de las Islas tenían un precio inferior, señal de que cuando llegaban al mercado de los esclavos de Génova estaban todavía algo moradas. Mientras que el valor de las mujeres blancas de Europa oriental era de 184 liras, las canarias se compraban por solo 129 liras y las negras por mucho menos. GIOFfrì, D.: Il mercato degli schiavi a Genova nel secolo XV, (1971), p. 141.

90 Whitehead, N.L. "Carib canibalism. The historical evidence», Journal de la Société des Américastes, t. 70, 1984. pp. 69-87.

${ }^{91}$ Muraro, M.: "The Moors of the clock tower of Venice and their sculptor», The art Bulletin, vol. 66, n. ${ }^{\circ}$ pp. 603-609.

92 Alonso, M.R.: «La luz llega del este». La Provincia, Las Palmas de Gran Canaria, 13 de marzo de 1999.

${ }_{93}$ ScORY, Edmund Scory (1526): «Extracts taken out of the Observations of the Right Worshipfull Sir Edmond Scory», en Quartapelle, A. op. cit., p. 171.

${ }_{94}$ De acuerdo con los históricos del arte la estatua del personaje más anciano, y que toca la campana dos minutos antes de la hora, representaría al tiempo pasado. El más joven representaría al tiempo presente. 

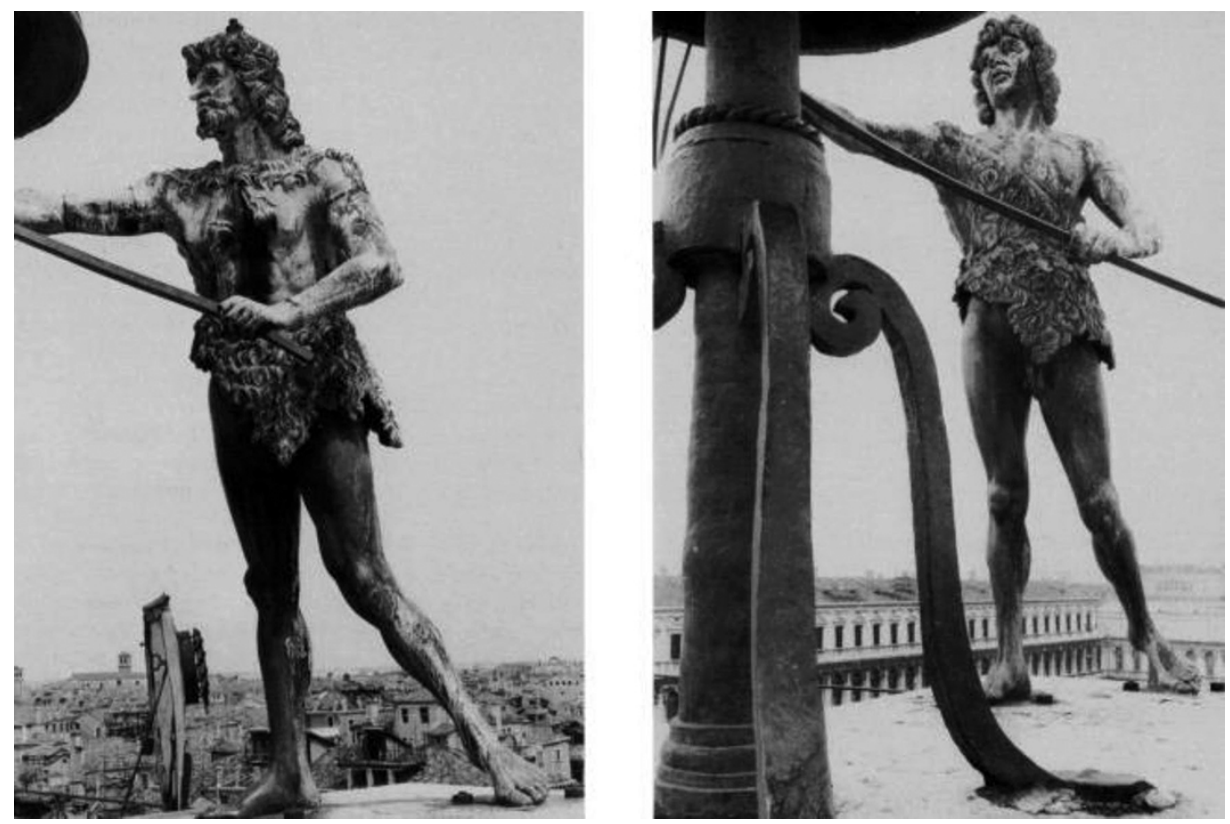

Foto 3. Detalle de los Do Mori de la Torre dell'Orologio en Venecia.

bierto en 1870. Desafortunadamente, las extremidades de esta pintura fueron recortadas porque estaban deterioradas. Sin embargo, el que hizo esta operación afirmó que

en el lado derecho aparecía la cabeza de un moro o árabe con birrete colorado que (...) era sin duda alguna la efigie del rey sarraceno o bereber de las Canarias, que fue regalado a la Señoría por los Reyes de España ${ }^{95}$.

Sin Embargo, la imagen que con más probabilidad representa al «rey de Tenerife» se encuentra en un fresco en la Scoletta de la basílica del Carmine de Padua. La obra el Sposalizio di Maria (Giulio Campagnola, 1505-1507) presenta en el lado izquierdo a un grupo de personas que asisten a la ceremonia.

Entre estas figuras se ha reconocido al pintor Mantegna, el hombre con los cabellos blancos, al propio Campagnola, en primer plano, y a la derecha al pintor alemán Albrecht Durer, que visitó Padua en 1505. Esta circunstancia ha hecho pensar a los críticos del arte que también los otros personajes presentes en la pin-

95 Rainieri, S.: "Cristoforo Colombo, la sua persona ed i suoi ritratti», Rivista Marittima (1890), en Asensio, J.M.: Cristobal Colón: su vida, sus viajes, sus descubrimientos (1891). p. 869. 


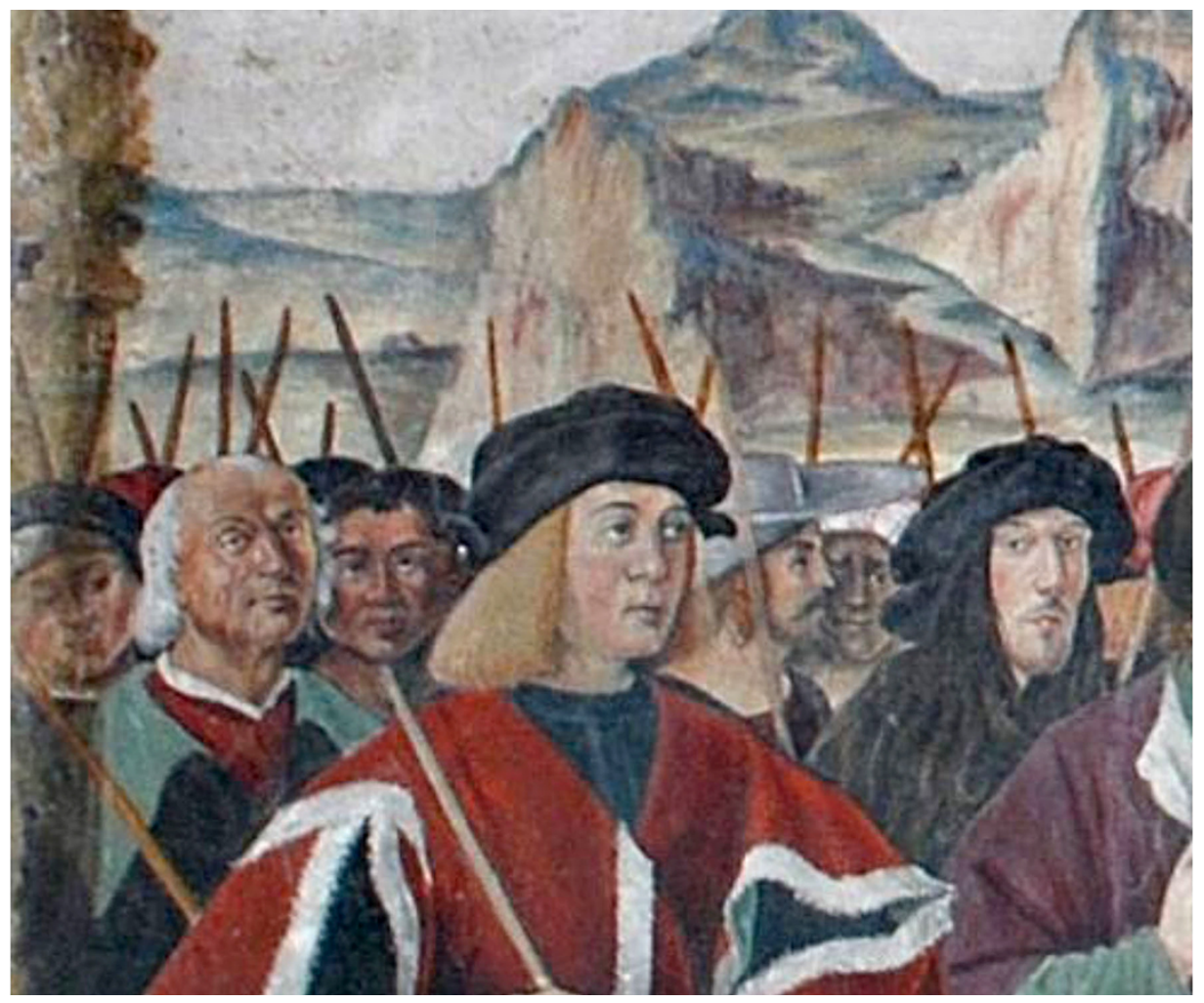

Foto 4. Padua-Scoletta del Carmine -Sposalizio della Vergine- 1505/1507.

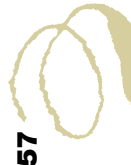

tura pudieron ser hombres ilustres que vivían en Padua en la época, entre los cuales podía, tal vez, encontrarse el «rey de Tenerife» ${ }^{96}$.

En efecto, al centro de la pintura aparece la cara de un hombre de piel morena con cara ancha y chata, cuyo semblante recuerda la fisionomía amerindia de los indios descritos en por Colón en su diario, gente muy fermosa, los cabellos no crespos, salvo corredios y gruesos, como sedas de cavallo, y todos de la frente y cabeça muy ancha, más que otra generación que fasta aqui aya visto.

Desafortunadamente, de la historia del fresco nos no ha llegado ningún documento que pueda confirmar esta posibilidad.

${ }^{96}$ Puppi, L.: Il re delle isole fortunate ed altre storie vere tra le meraviglie dell'arte, Angelo Colla Editore (2010). DAniele, E.: «Il re cannibale a Padova» en Padova ed il suo territorio, n. ${ }^{\circ} 180$, agosto 2016, pp. 17-21. 


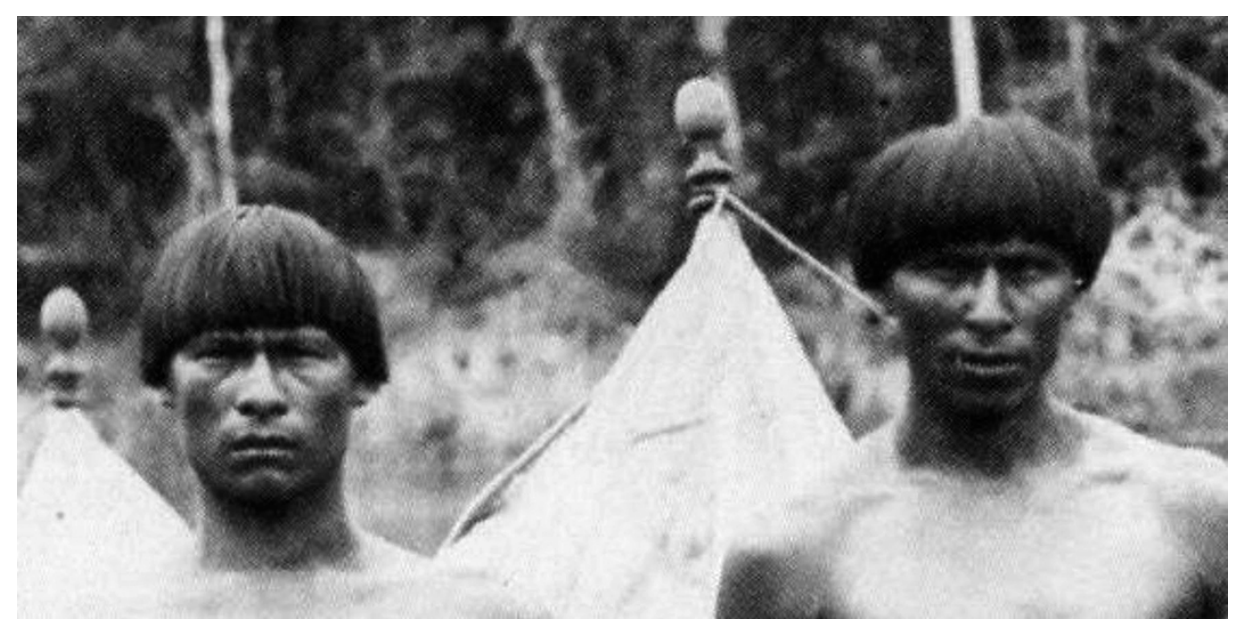

Foto 5. Indios del delta del Orinoco en 1894.

Por último, como curiosidad, pueden recordarse las doce estatuas que representan a unos indios de diferentes partes de Sudamérica que adornan el jardín de la mansión al Ponte della Brenta Vecchia cerca de Venecia. Esculpidas en 1715, su peculiaridad es que el comisionista del inusual grupo marmóreo fue la familia Contarini, probablemente los descendientes de aquel capitán Piero Contarini, apodado el pelirrojo, que trajo al «rey de Canaria» a Venecia en 1497, quienes tal vez quisieron recordar de esta forma la hazaña de su ilustre antepasado ${ }^{97}$.

\section{CONCLUSIONES}

Los documentos encontrados hasta ahora parecen presentar dos realidades en abierta contradicción. Las fuentes españolas de la época atestiguan que los españoles habían donado, o querían donar, a la Serenissima un «rey de Tenerife». Y también los historiadores de los siglos siguientes confirman esta reconstrucción de los hechos. Por ejemplo, en 1580 Jerónimo Zurita, en su Historia del Rey Don Hernando, escribe que fue traido el Rey (de Tenerife) «en memoria de aquella victoria, a España: al qual el Rey embió a la Señoría de Venecia, en señal de gran amistad con su embaxador Francisco Capelo, quando volvió a Venecia de su embaxada $»^{98}$. Y unas

${ }^{97}$ Camerlengo, L.: «Gli dei e i selvaggi. Esempi di scultura nei giardini tra Sei e Settecento» en Scultura in villa a cura di Monicelli F. Fondazione Cariverona (2004), p. 155.

${ }_{98}$ Zurita registra por error este acontecimiento en el año de 1495. Zurita, J.: História del Rey Don Hernando, Zaragoza 1580, Livro II, cap. xv. 
páginas más adelante añade que «entonces Francisco Capello, que era su embaxador, se volvió a Venecia y llevó en presente a la Señoria el rey de la isla de Tenerife»"

Sin embargo, analizando las fuentes venecianas se puede afirmar que en la ciudad de la Serenissima habían recibido, o estaban convencidos de haber recibido, como don de los reyes de España, un rey de Canaria por trovar, o sea un cacique del Nuevo Mundo:

1. Sanudo, en junio de 1497, al sintetizar la deliberación de los Savi di Terra Ferma, define claramente a nuestro personaje recién llegado a Venecia como re di Canaria preso in le Indie.

2. Sanudo y Malipiero afirman que el «rey» era antropófago y que comía la carne de los enemigos o de los ajusticiados.

3. Sanudo y Malipiero, al describir el «rey» que tuvieron la oportunidad de observar personalmente, afirman que era de piel morena y de tez obscura, circunstancia difícilmente compatible con un rey de Tenerife caucásico y de piel clara.

¿Cuál de estas dos verdades, la española o la veneciana, es históricamente la correcta? Los documentos presentados desafortunadamente no parecen permitir llegar a una solución definitiva acerca de la identidad del «rey de Tenerife». Probablemente, fue en verdad el mencey más famoso y bello del que habla el embajador Capello en su despacho de noviembre de 1496. Probablemente, los venecianos solo se confundieron entre las Islas Canarias y las Islas Canarias por trovar, debido a su ignorancia de la geografía atlántica.

Ciertamente, los nuevos documentos presentados dejan abierta la posibilidad de que antes de la salida del embajador Capello hacia Venecia los Reyes Católicos, por algún motivo desconocido, puedan haber decidido cambiar su «don", enviando a la ciudad de la Serenissima un cacique-caníbal del Caribe en lugar del mencey de Tenerife, el que habían prometido. Circunstancia que parece confirmada por Núnez de la Peńa, que en su Conquista y antigüedades de las islas de la Gran Canaria escribe que

en el ańo de mil y cuatrocientos y noventa y siete, llevó el adelantado los nueve Reyes a la presencia de los Católicos Reyes, que se halagaron de verlos, y fueron bien recibidos, y sus Magestades les hizieron muchas mercedes y volvieron a Thenerife ${ }^{100}$.

ReCiBido: 2-3-2020; ACEPTADO: 11-6-2020

99 Ibidem. Livro II, cap. XXXVII.

100 Núñez de la Peña, J.: Conquista y antigüedades de las islas de la Gran Canaria, Madrid, 1676, cap. XVI, p. 163. 
